(1)

CrossMark

\title{
Effect of morphine on breathlessness and exercise endurance in advanced COPD: a randomised crossover trial
}

\begin{abstract}
Sara J. Abdallah ${ }^{1}$, Courtney Wilkinson-Maitland ${ }^{1}$, Nathalie Saad ${ }^{2,3}$, Pei Zhi Li ${ }^{4}$, Benjamin M. Smith ${ }^{1,3,4,5,6,7,8,9}$, Jean Bourbeau ${ }^{3,4,5,6,7,8,9}$ and Dennis Jensen ${ }^{1,3,4,5,6,7,8,9}$

Affiliations: ${ }^{1}$ Clinical Exercise and Respiratory Physiology Laboratory, Dept of Kinesiology and Physical Education, McGill University, Montréal, QC, Canada. ${ }^{2} J e w i s h$ General Hospital and Mount Sinai Hospital Montréal, Montréal, QC, Canada. ${ }^{3}$ Dept of Medicine, Respiratory Division, McGill University, Montréal, QC, Canada. ${ }^{4}$ Respiratory Epidemiology and Clinical Research Unit, Montréal Chest Institute, McGill University Health Centre, Montréal, QC, Canada. ${ }^{5}$ Meakins-Christie Laboratories, Research Institute of the McGill University Health Centre (RI-MUHC), Montréal, QC, Canada. ${ }^{6}$ McConnell Centre for Innovative Medicine, RIMUHC, Montréal, QC, Canada. ${ }^{7}$ Centre for Outcomes Research and Evaluation, RI-MUHC, Montréal, QC, Canada. ${ }^{8}$ Translational Research in Respiratory Diseases Program, RI-MUHC, Montréal, QC, Canada. ${ }^{9}$ Research Centre for Physical Activity and Health, McGill University, Montréal, QC, Canada.
\end{abstract}

Correspondence: Dennis Jensen, Dept of Kinesiology and Physical Education, 475 Pine Avenue West, Montréal, QC, Canada, H2W 1S4. E-mail: dennis.jensenamcgill.ca

@ERSpublications

Immediate-release oral morphine decreased exertional breathlessness and improved exercise endurance in advanced COPD http://ow.ly/mrHQ30dS2qS

Cite this article as: Abdallah SJ, Wilkinson-Maitland C, Saad N, et al. Effect of morphine on breathlessness and exercise endurance in advanced COPD: a randomised crossover trial. Eur Respir J 2017; 50: 1701235 [https://doi.org/10.1183/13993003.01235-2017].

ABSTRACT The objective of the present study was to evaluate the effect of morphine on exertional breathlessness and exercise endurance in advanced chronic obstructive pulmonary disease (COPD).

In a randomised crossover trial, we compared the acute effect of immediate-release oral morphine versus placebo on physiological and perceptual responses during constant-load cardiopulmonary cycle exercise testing (CPET) in 20 adults with advanced COPD and chronic breathlessness syndrome.

Compared with placebo, morphine reduced exertional breathlessness at isotime by $1.2 \pm 0.4$ Borg units and increased exercise endurance time by $2.5 \pm 0.9 \mathrm{~min}$ (both $\mathrm{p} \leqslant 0.014$ ). During exercise at isotime, morphine decreased ventilation by $1.3 \pm 0.5 \mathrm{~L} \cdot \mathrm{min}^{-1}$ and breathing frequency by $2.0 \pm 0.9 \mathrm{breaths} \cdot \mathrm{min}^{-1}$ (both $\mathrm{p} \leqslant 0.041$ ). Compared with placebo, morphine decreased exertional breathlessness at isotime by $\geqslant 1$ Borg unit in 11 participants (responders) and by $<1$ Borg unit in nine participants (non-responders). Baseline participant characteristics, including pulmonary function and cardiorespiratory fitness, were similar between responders and non-responders. A higher percentage of responders versus non-responders stopped incremental CPET due to intolerable breathlessness: 82 versus $33 \%$ ( $\mathrm{p}=0.028)$.

Immediate-release oral morphine improved exertional breathlessness and exercise endurance in some, but not all, adults with advanced COPD. The locus of symptom-limitation on laboratory-based CPET may help to identify patients most likely to benefit from morphine.

This article has supplementary material available from erj.ersjournals.com

Received: March 182017 | Accepted after revision: July 212017

Support statement: S.J. Abdallah was funded by a Ph.D. Recruitment Award (McGill University), a Ruth Hoyt Cameron Fellowship, a Max Bell Fellowship, and a Frederik Banting and Charles Best Graduate Scholarship - Doctoral Award (CGS-D) from the Canadian Institutes of Health Research (201410GSD-347900-243684). B.M. Smith was supported by a Chercheurs-Boursiers Cliniciens Junior 1 salary award from the Fonds de recherche du Québec-Santé. D. Jensen was supported by a Chercheurs-Boursiers Junior 1 salary award from the Fonds de Recherche du Québec-Santé, a William Dawson Research Scholar Award from McGill University, and a Canada Research Chair in Clinical Exercise and Respiratory Physiology (Tier 2) from the Canadian Institutes of Health Research. Funding information for this article has been deposited with the Crossref Funder Registry.

Conflict of interest: Disclosures can be found alongside this article at erj.ersjournals.com

Copyright @ERS 2017 


\section{Introduction}

Breathlessness and exercise intolerance are independently associated with increased morbidity and mortality in chronic obstructive pulmonary disease (COPD) [1]. Despite optimal treatment of their underlying disease with bronchodilators, corticosteroids and/or phosphodiesterase inhibitors, 46-91\% of patients with severe-to-very-severe COPD suffer from chronic and disabling breathlessness at rest and on minimal exertion [2-4]; i.e., chronic breathlessness syndrome [5]. Therefore, symptom-specific therapies that alleviate refractory breathlessness and improve exercise capacity are needed to enhance health outcomes in advanced COPD.

A systematic review and meta-analysis by Екsтrом et al. [6] recently concluded that systemic low-dose opioids are safe and effective for decreasing refractory breathlessness but do not improve exercise capacity in advanced COPD. Importantly, published studies have provided little insight into the mechanism(s) mediating opioid-induced relief of breathlessness in COPD, although reductions in ventilation ( $\left.V^{\prime} \mathrm{E}\right)$ via reduced central neural respiratory drive and/or a blunted central perception of breathlessness have been proposed [7-10]. A better understanding of the physiological mechanism(s) of action of systemic opioids on breathlessness is essential to optimising symptom control in advanced COPD.

Although Canadian, American, European and international clinical practice guidelines support the use of systemic low-dose opioids for decreasing refractory breathlessness in advanced COPD [11-14], many physicians do not prescribe opioids for breathlessness [15] due to fear of adverse side-effects (e.g. respiratory depression), insufficient scientific evidence supporting a benefit of opioids on refractory breathlessness and an inability to predict which patients will respond to opioids $[16,17]$.

The primary objective of this randomised crossover trial was to evaluate the acute effect of oral morphine on exertional breathlessness and exercise endurance in advanced COPD. Our secondary objective was to elucidate the physiological mechanism(s) of action of oral morphine on exertional breathlessness and exercise endurance in advanced COPD. We compared detailed physiological and perceptual responses to cycle endurance exercise testing after single-dose administration of immediate-release oral morphine and placebo in participants with advanced COPD and chronic breathlessness syndrome. We hypothesised that oral morphine versus placebo would be associated with clinically meaningful improvements in exertional breathlessness and exercise endurance, independent of opioid-related side effects, $\mathrm{CO}_{2}$ retention and concurrent improvements in the physiological response to exercise.

\section{Materials and methods}

\section{Participants}

Participants included men and women aged $\geqslant 40$ years with Global Initiative for Obstructive Lung Disease stage 3 or 4 COPD [14] and chronic breathlessness syndrome [5], defined as a modified Medical Research Council dyspnoea score of $\geqslant 3$ [18], a baseline dyspnoea index focal score of $\leqslant 6$ [19] and/or an oxygen cost diagram rating of $\leqslant 50 \%$ full scale [20] despite optimal treatment with bronchodilators, corticosteroids and/or phosphodiesterase inhibitors [14]. See the online data supplement for more information on eligibility criteria.

\section{Study design}

This single-centre, randomised, double-blind, placebo-controlled, crossover trial consisted of two intervention periods separated by a washout period of $\geqslant 48 \mathrm{~h}$ (figure 1). Participants were randomised in a $1: 1$ ratio to receive immediate-release oral morphine sulphate $\left(0.1 \mathrm{mg} \cdot \mathrm{kg}^{-1}\right.$ body mass to a maximum dose of $10 \mathrm{mg}$ (Statex; Paladin Labs Inc., Montreal, QC, Canada)) or diluted simple syrup (placebo) prepared in $250 \mathrm{~mL}$ of orange juice. The study received ethical approval from Health Canada and the Research Institute of the McGill University Health Centre.

After providing written informed consent, participants completed a screening/familiarisation visit followed by two randomly assigned treatment visits. Visit 1 included: evaluation of participant-reported breathlessness [18-20], health status [21] and anxiety/depression [22]; measurement of arterialised capillary carbon dioxide tension $\left(\mathrm{PacCO}_{2}\right)$ at rest; post-bronchodilator $(400 \mu \mathrm{g}$ salbutamol) pulmonary function testing; and a symptom-limited incremental $\left(5-\mathrm{W} \cdot \mathrm{min}^{-1}\right)$ cardiopulmonary cycle exercise test (CPET) to determine peak power output (PPO). At the start of visits 2 and 3, participants inhaled $400 \mu \mathrm{g}$ of salbutamol to standardise the time since last bronchodilator administration. 15 min thereafter, participants completed the opioid-related symptom distress scale (ORSDS) [23, 24] followed by blood sampling for measurement of $\mathrm{PacCO}_{2}$ and of plasma concentrations of morphine ([MOR]), morphine-3-glucuronide ([M3G]) and morphine-6-glucuronide ([M6G]). Participants were then administered oral morphine or placebo. $30 \mathrm{~min}$ thereafter, participants completed the ORSDS and blood for measurement of $\mathrm{PacCO}_{2}$, [MOR], [M3G] and [M6G] was collected. Participants then completed a symptom-limited constant-load cycle CPET at 75\% PPO. 


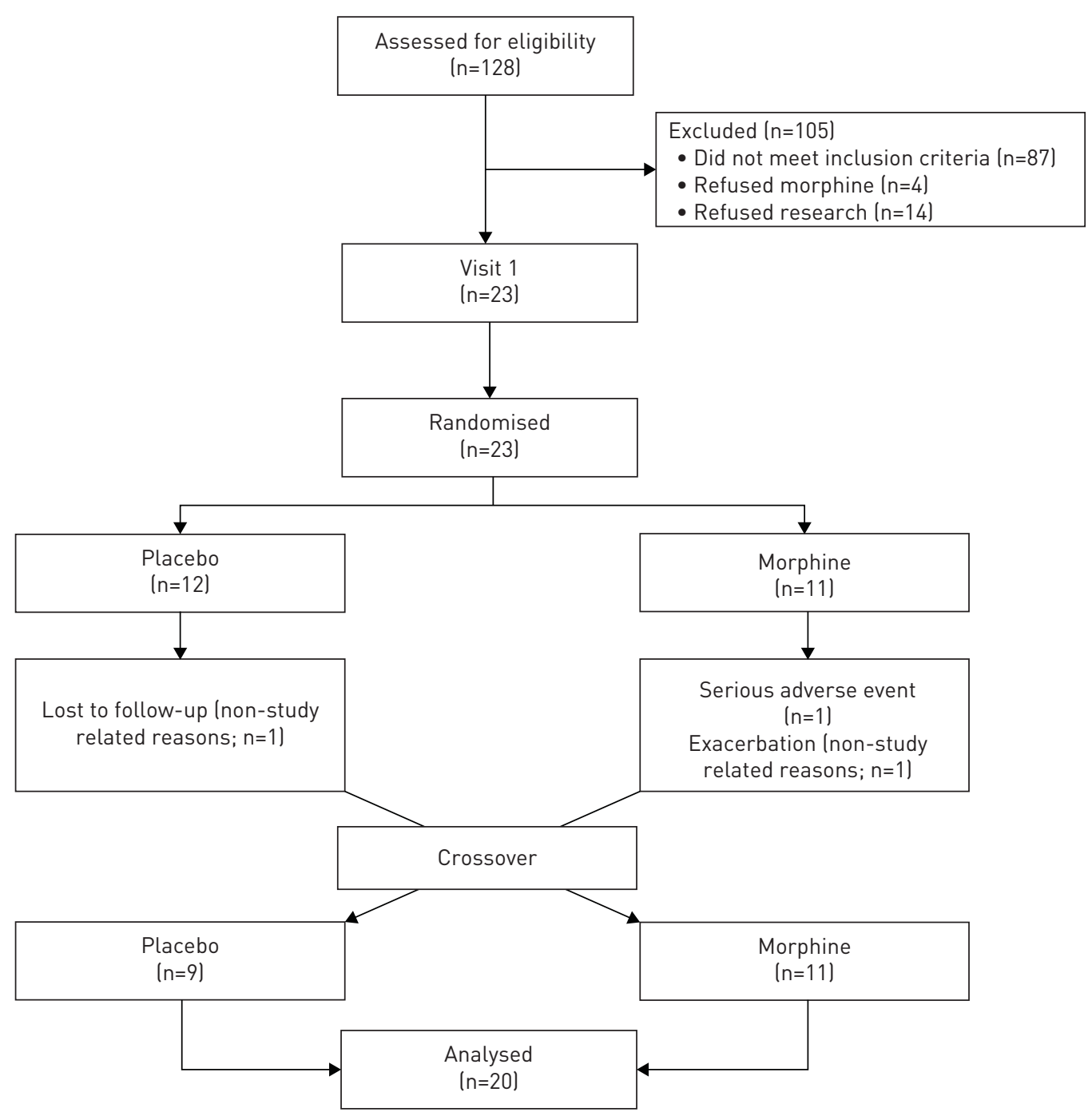

FIGURE 1 CONSORT diagram of the study population.

\section{Procedures}

Spirometry, plethysmography and single-breath diffusion capacity of the lung for carbon monoxide were performed using automated equipment and recommended techniques [25-28]. Exercise tests were conducted on an electronically braked cycle ergometer using a computerised CPET system. Cardiac, metabolic, breathing pattern and gas exchange parameters were collected and analysed as previously described [29]. Inspiratory capacity manoeuvres were performed at rest, every 2 min during CPET and at end-exercise [30]. Using Borg's modified 0-10 category ratio scale [31], participants rated the intensity and unpleasantness of their breathlessness, as well as the intensity of their leg discomfort at rest, every 2 min during CPET, and at end-exercise [29, 32]. In a subgroup of seven consenting participants, breath-by-breath measures of the crural diaphragm electromyogram (EMGdi) were recorded from a multi-pair oesophageal electrode catheter and analysed using published methods [32, 33]. Participants verbalised their main reason(s) for stopping exercise, quantified the percentage contribution of breathlessness and leg discomfort to exercise cessation, and identified qualitative phrases that best described their breathlessness at end-exercise [34]. Each participant's blinded treatment preference was assessed at the end of visit 3 . See the online data supplement for more information on experimental procedures.

\section{Outcome variables}

The primary outcome was the post-dose difference in breathlessness intensity ratings during exercise at isotime, defined as the highest equivalent 2-min interval of exercise completed by a given participant during each of the constant-load CPETs. The co-primary outcome was the post-dose difference in exercise endurance time (EET), defined as the duration of loaded pedalling during constant-load CPET. See online data supplement for details on secondary outcome variables. 


\section{Statistical analyses}

Using a two-tailed paired subject formula with $\alpha=0.05, \beta=0.90$ and an expected effect size of 0.80 [35], we estimated that 20 participants were needed to detect a minimal clinically important difference (MCID) of 1 Borg unit in breathlessness intensity during exercise at isotime [36] and of $101 \mathrm{~s}$ in EET [37] after taking morphine versus placebo.

All participants who completed both morphine and placebo arms of the trial were included in the analysis. Linear mixed-models regression with random intercepts was used to analyse post-dose differences in EET as well as in all physiological and perceptual responses to constant-load CPET, accounting for period and sequence effects. A secondary analysis was conducted after examination of the data showed that 11 participants had a morphine-induced decrease in breathlessness intensity at isotime by the MCID of $\geqslant 1$ Borg unit (responders) compared with the remaining nine participants who did not (non-responders). Statistical significance was set at $\mathrm{p}<0.05$. See the online data supplement for additional information on the statistical analyses performed.

\section{Results}

23 out of 128 participants assessed for eligibility were randomised (figure 1). Two of these 23 participants were lost during follow-up for non-study-related reasons, while one was lost following a serious adverse event. Baseline characteristics of the 20 participants who completed the trial are presented in tables 1 and 2.

\begin{tabular}{|c|c|}
\hline Parameter & Value \\
\hline Male:female $n$ & $15: 5$ \\
\hline Age years & $63.6 \pm 7.1$ \\
\hline Height $\mathrm{cm}$ & $169.0 \pm 8.3$ \\
\hline Body mass kg & $71.6 \pm 14.4$ \\
\hline Body mass index $\mathrm{kg} \cdot \mathrm{m}^{-2}$ & $25.3 \pm 5.2$ \\
\hline $\mathrm{PacCO}_{2} \mathrm{mmHg}$ (range) ${ }^{\#}$ & $37.7 \pm 3.4(32-45)$ \\
\hline Smoking history pack-years & $59.3 \pm 22.8$ \\
\hline GOLD stage $3: 4 \mathrm{n}$ & $12: 8$ \\
\hline \multicolumn{2}{|l|}{ Post-bronchodilator pulmonary function } \\
\hline $\mathrm{FEV}_{1} \mathrm{~L}(\%$ predicted) & $0.93 \pm 0.21(35 \pm 9)$ \\
\hline $\mathrm{FEV}_{1} / \mathrm{FVC} \%$ & $36.3 \pm 10.3$ \\
\hline TLC L (\% predicted) & $7.79 \pm 1.70(126 \pm 17)$ \\
\hline RV L (\% predicted) & $4.70 \pm 1.40(217 \pm 57)$ \\
\hline FRC L (\% predicted) & $5.68 \pm 1.57(174 \pm 38)$ \\
\hline IC L (\% predicted) & $2.08 \pm 0.61(72 \pm 17)$ \\
\hline$D \mathrm{LCO} \mathrm{mL} \cdot \min \cdot \mathrm{mmHg}^{-1}(\% \text { predicted })^{\pi}$ & $12.9 \pm 6.2(52 \pm 30)$ \\
\hline $\mathrm{sRaw} \mathrm{cmH}_{2} \mathrm{O} \cdot \mathrm{L} \cdot \mathrm{S}^{-1}$ (\% predicted) ${ }^{\#}$ & $46.4 \pm 35.8(949 \pm 821)$ \\
\hline \multicolumn{2}{|l|}{ Breathlessness and health status } \\
\hline mMRC score 0-4 & $3.0 \pm 0.6$ \\
\hline BDI focal score out of 12 & $3.9 \pm 1.9$ \\
\hline Oxygen cost diagram $\%$ full scale & $39 \pm 16$ \\
\hline CAT score out of 40 & $21.3 \pm 6.4$ \\
\hline CAT breathlessness item out of 5 & $4.1 \pm 0.9$ \\
\hline CAT activity limitation item out of 5 & $3.3 \pm 1.5$ \\
\hline HADS score out of 42 & $12.2 \pm 6.1$ \\
\hline \multicolumn{2}{|l|}{ COPD medication summary } \\
\hline LABA+LAMA n & 4 \\
\hline LABA+LAMA+ICS n & 14 \\
\hline LABA+LAMA+PI n & 1 \\
\hline$L A B A+L A M A+I C S+P I n$ & 1 \\
\hline
\end{tabular}

Data are presented as mean $\pm \mathrm{SD}$, unless otherwise stated. ${ }^{\#}: \mathrm{n}=18$. १: $n=17 . \mathrm{PacCO}_{2}$ : partial pressure of carbon dioxide in arterialised capillary blood; GOLD: Global Initiative for Obstructive Lung Disease; FEV1: forced expiratory volume in $1 \mathrm{~s} ; \mathrm{FEV}_{1} / \mathrm{FVC}$, forced expiratory volume in $1 \mathrm{~s}$ to forced vital capacity ratio; TLC: total lung capacity; RV: residual volume; FRC: functional residual capacity; IC: inspiratory capacity; $D\llcorner C 0$ : diffusing capacity of the lung for carbon monoxide; sRaw: specific airway resistance; mMRC: modified Medical Research Council Dyspnoea Scale; BDI: Baseline Dyspnoea Index; CAT: COPD Assessment Test; HADS: Hospital Anxiety and Depression Scale; LABA: long-acting $\beta_{2}$ agonist; LAMA: long-acting muscarinic antagonist; ICS: inhaled corticosteroid; PI: phosphodiesterase inhibitor. 


\section{Primary outcomes}

There was no statistically significant sequence or period effect of treatment. Compared with placebo, morphine (mean \pm SEM dose, 7.2 $\pm 3.2 \mathrm{mg}$ (range: 4.4-9.2 mg)) decreased breathlessness intensity ratings at isotime by $1.2 \pm 0.4$ Borg units $(\mathrm{p}=0.011$ ) (figure $2 \mathrm{a}, \mathrm{d}$ and $\mathrm{g}$, table 3 ) and increased EET by $2.5 \pm 0.9 \mathrm{~min}$ (148 $\pm 52 \mathrm{~s})$ or $41 \pm 13 \%(\mathrm{p}=0.014)$ (figure $2 \mathrm{f}$ and $\mathrm{i}$, table 3 ).

\section{Secondary outcomes}

Perceptual responses

Compared with placebo, morphine decreased breathlessness unpleasantness ratings by $1.4 \pm 0.4$ Borg units at isotime $(\mathrm{p}=0.003$ ) (figure $2 \mathrm{~b}$, e and $\mathrm{h}$, table 3 ), but had no effect on intensity ratings of leg discomfort at rest or during exercise (figure $2 c$, table 3 ). Despite differences in EET, breathlessness intensity and unpleasantness ratings were similar between treatments at end-exercise (figure $2 \mathrm{a}$ and $\mathrm{b}$, table 3 ).

Compared with placebo, morphine had no effect on the locus of symptom limitation (table 3), the selection frequency of breathlessness descriptors at end-exercise (see figure E1 in the online data supplement), and the relative contributions of breathlessness (morphine, $61 \pm 8 \%$ versus placebo, $66 \pm 8 \%$, $\mathrm{p}=0.260$ ) and leg discomfort (morphine, $19 \pm 6 \%$ versus placebo, $23 \pm 6 \%, \mathrm{p}=0.305$ ) to exercise cessation.

\section{Blood biochemistry}

Oral morphine increased plasma $[\mathrm{MOR}],[\mathrm{M} 3 \mathrm{G}]$ and $[\mathrm{M} 6 \mathrm{G}]$ (figure 3a). Morphine-induced changes in breathlessness intensity ratings at isotime and in EET were unrelated to plasma [MOR], [M3G] and [M6G] (Pearson $r \leqslant 0.43, p \geqslant 0.09$ for all). There was no treatment, time or treatment $\times$ time interaction effect for $\mathrm{PacCO}_{2}$ (figure 3b). There was also no evidence of $\mathrm{CO}_{2}$ retention at rest: all pre- and post-dose measurements of $\mathrm{PacCO}_{2}$ were $<50 \mathrm{mmHg}$ (figure 3b).

\section{Physiological responses}

With the exception of a small but significant increase in the end-tidal partial pressure of $\mathrm{CO}_{2}\left(\mathrm{PETCO}_{2}\right)$ by just $0.9 \pm 0.3 \mathrm{mmHg}(\mathrm{p}=0.002)$, morphine had no effect on physiological variables at rest (figure 4 , table 3 ). During exercise at isotime after taking morphine versus placebo, there were small but significant decreases

TABLE 2 Physiological and perceptual responses at the symptom-limited peak of incremental cycle exercise testing in adults with advanced chronic obstructive pulmonary disease and chronic breathlessness syndrome

\begin{tabular}{|c|c|}
\hline Parameter & Value \\
\hline Cycle exercise time min & $6.5 \pm 2.7$ \\
\hline Power output Watt (\% predicted) & $37.8 \pm 17.7(27 \pm 10)$ \\
\hline$V^{\prime} \mathrm{O}_{2} \mathrm{~mL} \cdot \mathrm{kg} \cdot \mathrm{min}^{-1}(\%$ predicted $)$ & $12.7 \pm 2.6(53 \pm 16)$ \\
\hline Heart rate beats. $\min ^{-1}(\%$ predicted $)$ & $113 \pm 22(67 \pm 13)$ \\
\hline Breathlessness intensity Borg units & $6.1 \pm 2.3$ \\
\hline Breathlessness unpleasantness Borg units & $6.3 \pm 2.1$ \\
\hline Leg discomfort Borg units & $5.6 \pm 3.2$ \\
\hline$V^{\prime} \mathrm{E} L \cdot \min ^{-1}(\%$ estimated MVV) & $31.3 \pm 7.9(97 \pm 17)$ \\
\hline$V_{T} \mathrm{~L}$ & $1.11 \pm 0.31$ \\
\hline$f R$ breaths $\cdot \min ^{-1}$ & $29.2 \pm 6.9$ \\
\hline$\Delta \mathrm{IC}$ from rest $\mathrm{L}$ & $-0.94 \pm 0.61$ \\
\hline IRV L & $0.29 \pm 0.20$ \\
\hline$V^{\prime} \mathrm{E} / V^{\prime} \mathrm{CO}_{2}$ & $37.9 \pm 1.5$ \\
\hline$P$ ETCO 2 mmHg & $36.4 \pm 5.0$ \\
\hline $\mathrm{SpO}_{2} \%$ & $93 \pm 3$ \\
\hline$\Delta \mathrm{SpO}_{2}$ from rest $\%$ & $-2.4 \pm 2.8$ \\
\hline \multicolumn{2}{|l|}{ Reasons for stopping exercise } \\
\hline Breathlessness $\mathrm{n}$ & 12 \\
\hline Leg discomfort $n$ & 1 \\
\hline Breathlessness and leg discomfort $\mathrm{n}$ & 7 \\
\hline
\end{tabular}

Data are presented as mean $\pm S D$, unless otherwise stated. $V^{\prime} O_{2}$ : rate of oxygen uptake; $V^{\prime} E$ : minute ventilation; MVV: maximal voluntary ventilation estimated as forced expiratory volume in $1 \mathrm{~s} \times 35 ; V_{\mathrm{T}}$ : tidal volume, fR: breathing frequency; $\Delta$ : exercise-induced change; IC: inspiratory capacity; IRV: inspiratory reserve volume; $V^{\prime} \mathrm{E} / V^{\prime} \mathrm{CO}_{2}$ : ventilatory equivalent for carbon dioxide; $P \mathrm{ETCO}_{2}$ : partial pressure of end-tidal carbon dioxide; $\mathrm{SpO}_{2}$ : oxygen saturation by pulse oximetry. 
a)

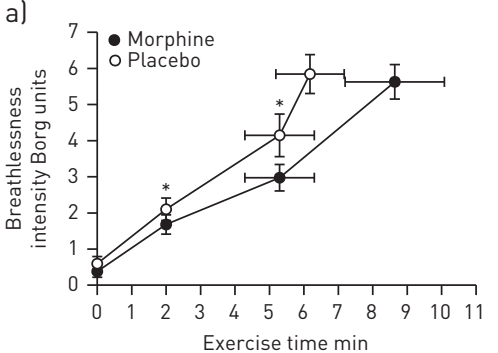

b)

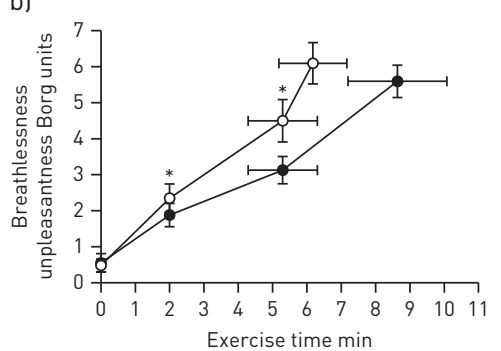

c)

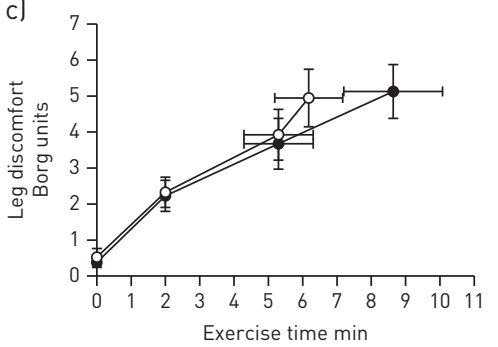

d)

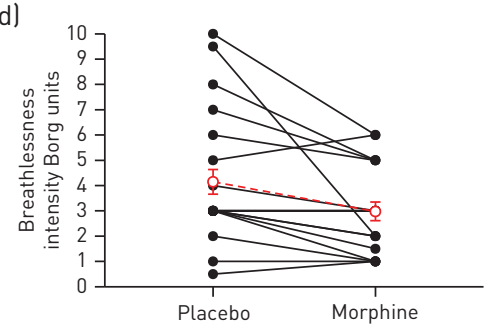

e)

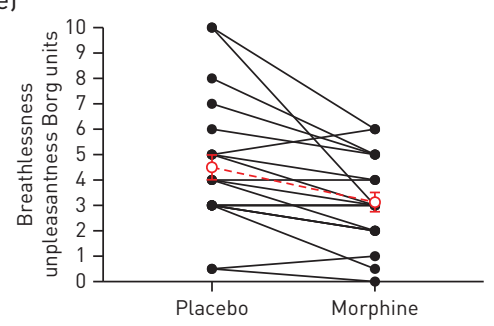

f)

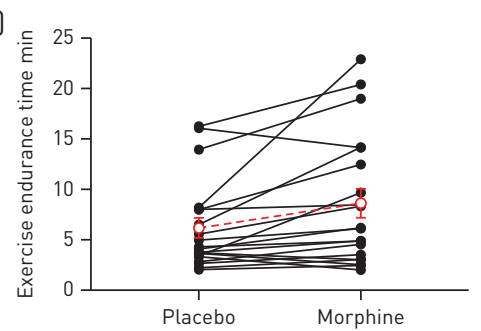

g)

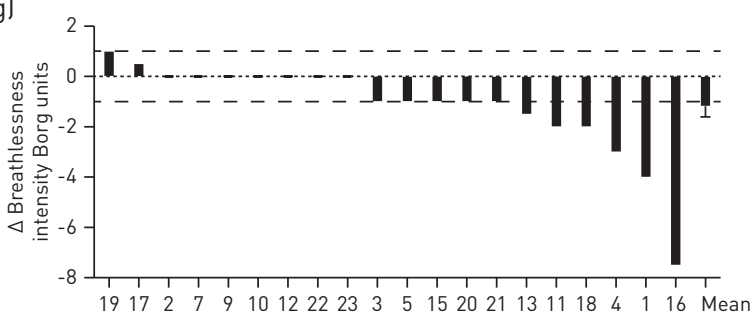

h)

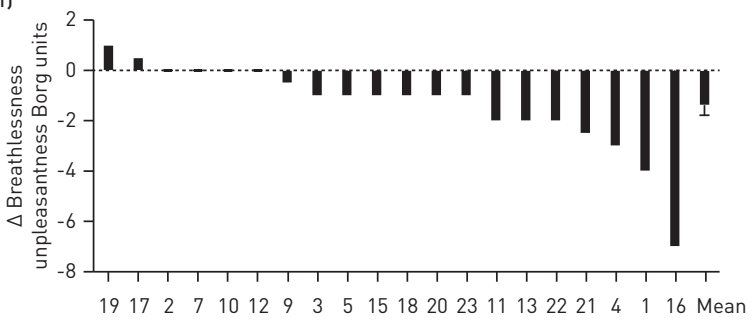

i)

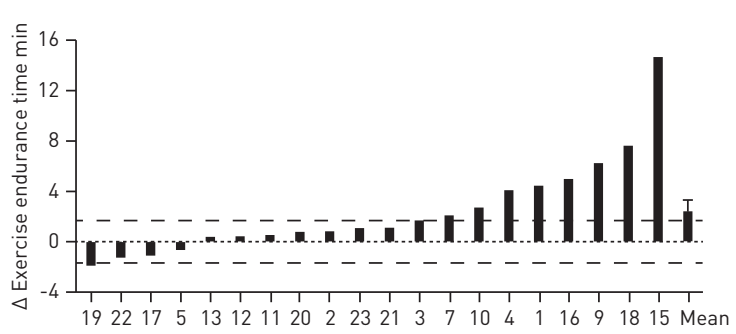

FIGURE 2 Effect of immediate-release oral morphine versus placebo on exertional breathlessness and exercise endurance in adults with advanced chronic obstructive pulmonary disease (COPD) and chronic breathlessness syndrome. Mean \pm SEM a) breathlessness intensity ratings, b) breathlessness unpleasantness ratings and c) leg discomfort ratings at rest and during constant-load cycle exercise testing at $75 \%$ of peak incremental power output. Individual participant post-dose values and post-dose differences in $\mathrm{d}$ and g) breathlessness intensity ratings during exercise at isotime, e and $\mathrm{h}$ ) breathlessness unpleasantness ratings during exercise at isotime and $\mathrm{f}$ and i) exercise endurance time, where red symbols with dashed horizontal lines in panels $d$, e and f) denote mean \pm SEM. Dashed horizontal lines in panels $g$ and i denote minimally clinically important difference for breathlessness intensity [36] and exercise endurance time [37]. $\Delta$ : post-dose difference (i.e., morphine minus placebo). *: $p<0.05$ versus placebo.

in $V^{\prime} \mathrm{E}(\mathrm{p}=0.031)$ and breathing frequency $(f \mathrm{R} ; \mathrm{p}=0.041)$ (figure 4, table 3). At peak exercise, $f \mathrm{R}$ decreased after taking morphine versus placebo $(\mathrm{p}=0.041)$ (figure $4 \mathrm{~b}$, table 3 ). Compared with placebo, morphine had no statistically significant effect on EMGdi or the EMGdi: $V^{\prime} \mathrm{E}$ ratio at any measurement time, although EMGdi was reduced by $\sim 13 \%$ during exercise at isotime after taking morphine versus placebo $(\mathrm{p}=0.061)$ (table 3).

\section{Opioid-related side effects and adverse events}

18 out of 20 participants reported no pre- to post-dose change in ORSDS ratings of headache, nausea, difficulty concentrating, drowsiness, lightheadedness/dizziness, confusion and fatigue after taking either morphine or placebo. One participant with no pre-dose symptoms reported lightheadedness/dizziness and difficulty concentrating $30 \mathrm{~min}$ after taking morphine, although the severity and bothersomeness of these symptoms were mild with ratings of $<20 \mathrm{~mm}$ on a $100-\mathrm{mm}$ visual analogue scale. Another participant with no pre-dose symptoms reported nausea and drowsiness $30 \mathrm{~min}$ after taking morphine and placebo, respectively. In both cases, the severity and bothersomeness of these symptoms were moderate, with visual analogue scale ratings of $<50 \mathrm{~mm}$. One serious adverse event occurred in a woman with an unreported intolerance to opioids. This participant experienced severe abdominal pain $20 \mathrm{~min}$ after taking morphine, was admitted to the emergency department, treated with epinephrine, and discharged $4 \mathrm{~h}$ after admission.

\section{Participant's blinded treatment preference}

15 out of 20 participants reported a preference for morphine over placebo for exercise: 12 participants volunteered that their breathing was easier during exercise, while three participants volunteered that exercise was less demanding. Three out of 20 participants reported a preference for placebo because they 
TABLE 3 Effect of immediate-release oral morphine $\left(0.1 \mathrm{mg} \cdot \mathrm{kg}^{-1}\right.$ body mass) versus placebo on physiological and perceptual responses at rest, at a standardised submaximal time during constant-load cycle exercise testing (isotime), and at the symptom-limited peak of constant-load cycle exercise testing in adults with advanced COPD and chronic breathlessness syndrome

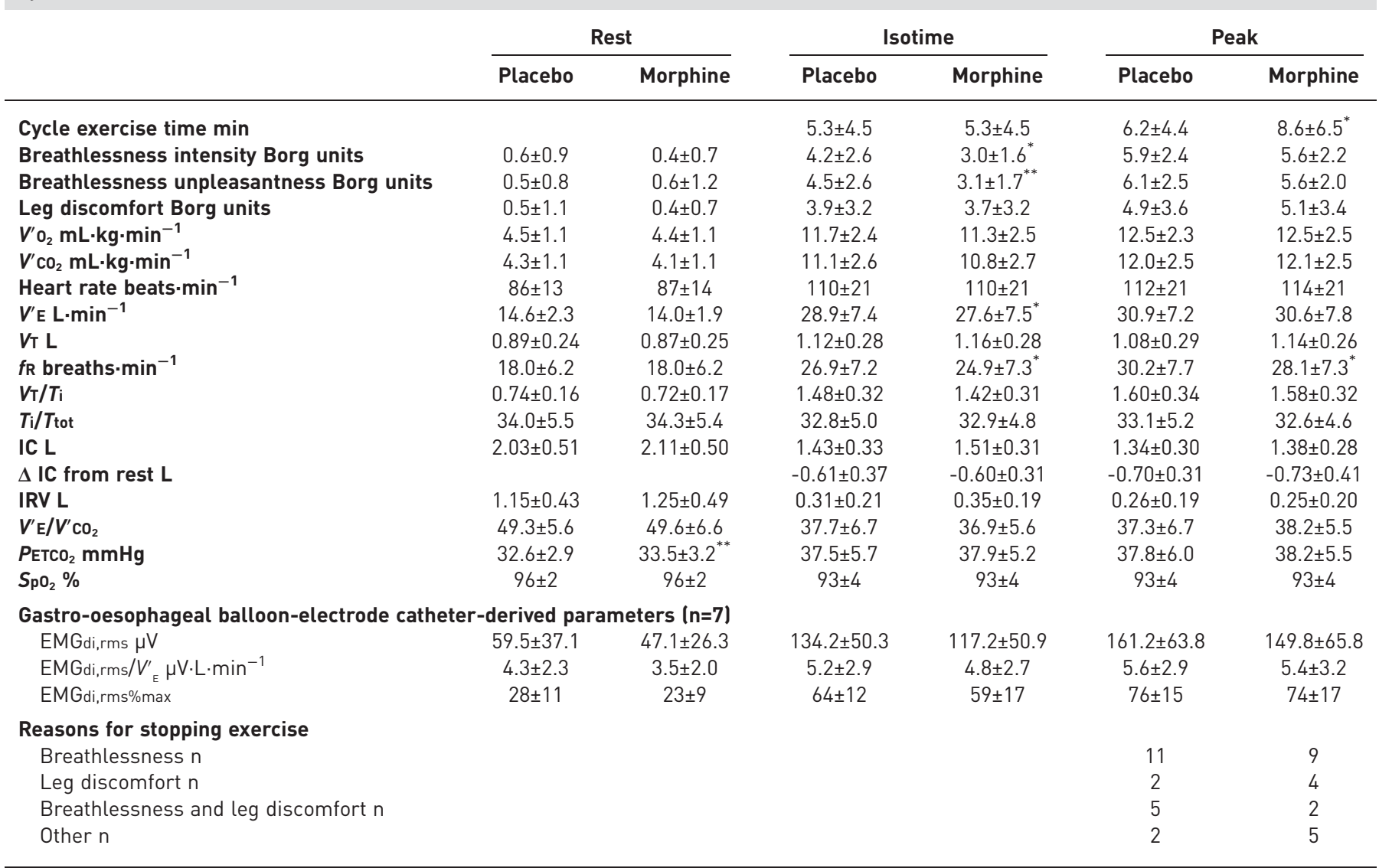

Data are presented as mean $\pm \mathrm{SD}$, unless otherwise stated. $V^{\prime} \mathrm{O}_{2}$ : rate of oxygen uptake; $V^{\prime} \mathrm{CO}_{2}$ : rate of carbon dioxide production; HR: heart rate; $V^{\prime} \mathrm{E}$ : minute ventilation; $V_{\mathrm{T}}$ : tidal volume; fR: breathing frequency; $V_{\mathrm{T}} / T_{\mathrm{i}}$ : mean tidal inspiratory flow, where $T_{\mathrm{i}}$ represents inspiratory time; $T_{\mathrm{i}} / T_{\text {tot: }}$ inspiratory duty cycle, where $T$ tot represents total breath duration; IC: inspiratory capacity; $\Delta$ : exercise-induced change; IRV: inspiratory reserve volume; $V^{\prime} \mathrm{E} / V^{\prime} \mathrm{CO}_{2}$ : ventilatory equivalent for carbon dioxide; $P \mathrm{ETCO} \mathrm{C}_{2}$ : partial pressure of end-tidal carbon dioxide; $\mathrm{SpO}_{2}$ : oxygen saturation by pulse oximetry; EMGdi,rms: root mean square of the crural diaphragm electromyogram; EMGdi,rms\%max: EMGdi,rms expressed as a percentage of maximum voluntary EMGdi,rms. ${ }^{*}: p<0.05$ and ${ }^{* *}: p<0.01$ versus placebo.

felt more prepared for the study visit (i.e. they received placebo at visit 3), while the remaining two participants reported no treatment preference.

Secondary analysis

Baseline characteristics were similar between responders and non-responders (see table E1 in the online data supplement), with the exception of forced expiratory volume in $1 \mathrm{~s}(\mathrm{FEV} 1)$ expressed as a percentage of predicted which tended to be lower in responders versus non-responders $(p=0.050)$.

Intensity and unpleasantness ratings of breathlessness were higher in responders versus non-responders at the symptom-limited peak of incremental CPET (intensity: $6.9 \pm 0.7$ versus $5.1 \pm 0.8$ Borg units ( $\mathrm{p}=0.077$ ); unpleasantness: $7.0 \pm 0.7$ versus $5.5 \pm 0.5$ Borg units $(\mathrm{p}=0.119)$ ) and constant-load CPET during the placebo treatment period (intensity: $6.8 \pm 0.8$ versus $4.7 \pm 0.6$ Borg units $(\mathrm{p}=0.046)$; unpleasantness: $7.1 \pm 0.8$ versus $4.9 \pm 0.6$ Borg units $(\mathrm{p}=0.050))$, even though PPO, EET, peak $V^{\prime} \mathrm{E}$ and peak rate of oxygen uptake $\left(V^{\prime} \mathrm{O}_{2}\right)$ were not significantly different between groups. A greater percentage of participants within the responders versus the non-responders subgroup identified intolerable breathlessness as their primary reason for stopping incremental CPET ( $82 \%$ ( $\mathrm{n}=9$ out of 11$)$ versus $33 \%(\mathrm{n}=3$ out of 9$), \mathrm{p}=0.028)$ and constant-load CPET during the placebo treatment period $(73 \%$ ( $n=8$ out of 11 ) versus $33 \%$ ( $n=3$ out of 9$), p=0.078)$. The relative contribution of intolerable breathlessness to the cessation of incremental CPET (76 \pm 6 versus $51 \pm 11 \%, \mathrm{p}=0.042)$ and constant-load CPET during the placebo treatment period $(76 \pm 9$ versus $52 \pm 13 \%$, $\mathrm{p}=0.139$ ) was also higher in responders versus non-responders. 

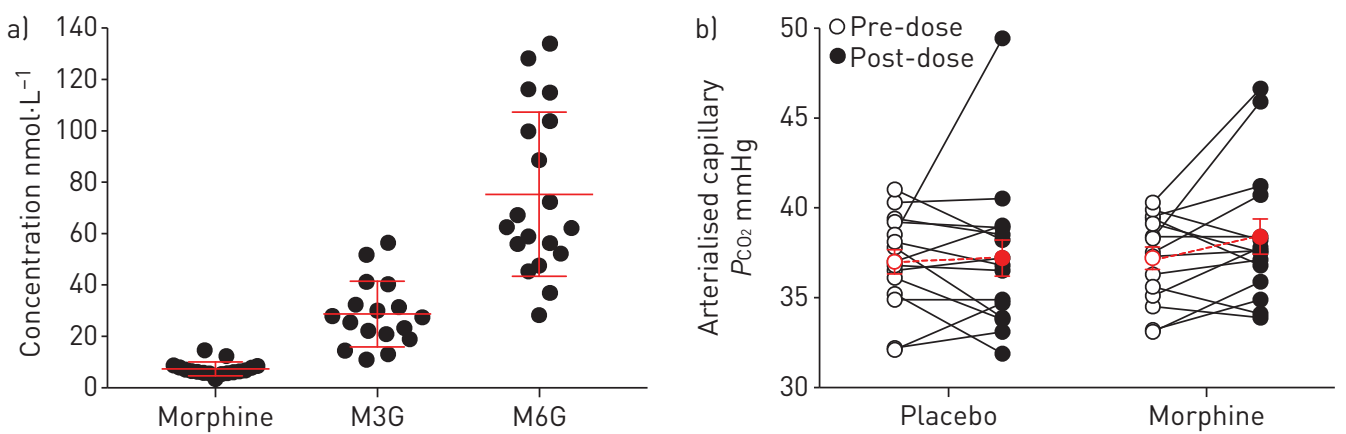

FIGURE 3 Effect of immediate-release oral morphine on blood biochemistry parameters in adults with advanced chronic obstructive pulmonary disease (COPD) and chronic breathlessness syndrome. a) Individual participant (closed circles; $\mathrm{n}=19$ ) and mean \pm SEM (red lines) plasma morphine, morphine-3-glucuronide (M3G) and morphine-6-glucuronide (M6G) concentrations measured 30-min after taking oral morphine. b) Arterialised capillary $\mathrm{CO}_{2}\left(\mathrm{PCO}_{2}\right)$ tension measurements made at rest before and 30 min after taking oral morphine and placebo among individual participants $(n=14)$, where red symbols with dashed horizontal lines denote mean士sem.

Plasma $[\mathrm{MOR}],[\mathrm{M} 3 \mathrm{G}]$ and $[\mathrm{M} 6 \mathrm{G}]$ were not different between responders and non-responders, while post-dose measures of $\mathrm{PacCO}_{2}$ were similar within- and between-groups (see figure E2 in the online data supplement). The effect of oral morphine versus placebo on breathlessness and selected ventilatory responses to constant-load CPET within responders and non-responders is shown in figure 5. After taking morphine versus placebo within the responder subgroup, EET increased by $3.6 \pm 1.3 \mathrm{~min}(\mathrm{p}=0.005)$, while breathlessness intensity and unpleasantness ratings during exercise at the highest equivalent isotime of $6.0 \pm 1.5$ min decreased by $2.3 \pm 0.6$ Borg units $(\mathrm{p}<0.001)$ and $2.3 \pm 0.6$ Borg units $(\mathrm{p}=0.001)$, respectively. Although the differences were not statistically significant, $f \mathrm{R}$ decreased by $3.2 \pm 1.4$ breaths $\cdot \mathrm{min}^{-1}$ and tidal volume (VT) increased by $0.08 \pm 0.04 \mathrm{~L}$ at isotime (with no corresponding change in $V^{\prime} \mathrm{E}$ ) after taking morphine versus placebo within responders. By contrast, morphine had no effect on EET or an effect on ventilatory and breathlessness responses to exercise within non-responders.
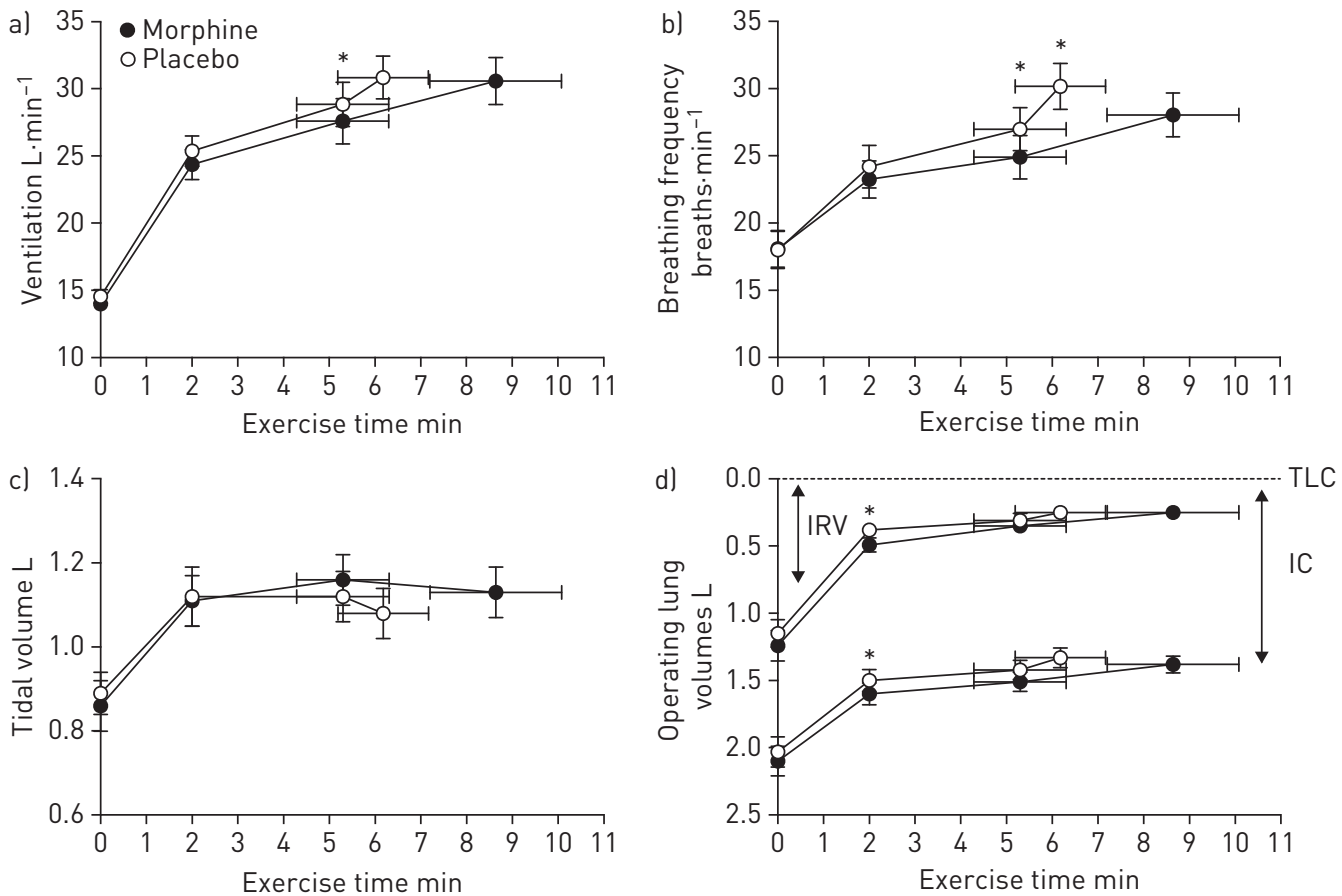

FIGURE 4 Effect of immediate-release oral morphine versus placebo on a) minute ventilation, b) breathing frequency, c) tidal volume and d) dynamic operating lung volume responses during constant-load cycle exercise testing at $75 \%$ of peak incremental power output in adults with advanced chronic obstructive pulmonary disease and chronic breathlessness syndrome. Data are presented as mean \pm SEM. IRV: inspiratory reserve volume; IC: inspiratory capacity; TLC: total lung capacity. ${ }^{*}: p<0.05$ versus placebo. 
Compared with placebo, morphine had no effect on either the locus of symptom limitation, the selection frequency of breathlessness descriptors at end-exercise or the percentage contributions of breathlessness and leg discomfort to exercise cessation within either responders or non-responders (data not shown).

\section{Discussion}

The main findings of this randomised crossover trial are as follows: 1) single-dose administration of immediate-release oral morphine versus placebo improved exertional breathlessness and exercise endurance among participants with advanced COPD and chronic breathlessness syndrome; 2) morphine-induced improvements in exertional breathlessness and exercise endurance were accompanied by small but statistically significant decreases in $V^{\prime} \mathrm{E}$ and $f_{\mathrm{R}}$ during exercise at isotime, without significant opioid-related side effects and/or gas exchange impairment at rest and during exercise; and 3) the locus of symptom-limitation on laboratory-based CPET may help to identify adults with advanced COPD and chronic breathlessness syndrome most likely to respond to morphine.

Compared with placebo, morphine decreased breathlessness intensity ratings during exercise at isotime by 1.2 Borg units and increased EET by $2.5 \mathrm{~min}(148 \mathrm{~s})$ or $41 \%$. The magnitudes of these improvements exceeded their respective MCIDs [36, 37] and were thus clinically meaningful. Our results are comparable to those of Woodcock et al. [10] and Light et al. [8] who respectively reported on the acute effect of single-dose oral dyhydrocodeine $\left(1 \mathrm{mg} \cdot \mathrm{kg}^{-1}\right.$ body mass) and oral morphine $\left(0.8 \mathrm{mg} \cdot \mathrm{kg}^{-1}\right.$ body mass $)$ on exertional breathlessness and exercise tolerance in advanced COPD.

It is noteworthy that improvements in exertional breathlessness and EET after taking morphine versus placebo occurred following apparent maximal or near maximal bronchodilatation with $400 \mu \mathrm{g}$ of inhaled salbutamol. Indeed, morphine-induced improvements in exertional breathlessness and EET could not be easily explained by improved dynamic respiratory mechanics.

In keeping with the results of WoODCOCK et al. [10] and LigHT et al. [8], single-dose administration of oral morphine versus placebo was associated with modest but statistically significant reductions in $V^{\prime} \mathrm{E}$ and $f_{\mathrm{R}}$ during exercise at isotime, which were accompanied by concomitant reductions in neural inspiratory drive to the crural diaphragm (i.e., EMGdi). These results are consistent with the known effect of systemic opioids on central and peripheral chemoreflex drives to breathe [7]. Importantly, the observed changes in $V^{\prime} \mathrm{E}, f \mathrm{R}$ and EMGdi occurred in the absence of any untoward effect of morphine on cardiac, metabolic and/ or gas exchange parameters at rest (e.g. $\left.\mathrm{PacCO}_{2}\right)$ and during exercise (e.g. $\mathrm{PETCO}_{2}$, oxygen saturation). In view of the observed reductions in $V^{\prime} \mathrm{E}, f \mathrm{R}, \mathrm{EMGdi}$ and the relatively preserved EMGdi: $V^{\prime} \mathrm{E}$ ratio during exercise at isotime after taking morphine versus placebo, we speculate that morphine-induced improvements in exertional breathlessness and EET reflected, at least in part, the awareness of reduced central neural respiratory drive as sensed by reduced central corollary discharge from brainstem respiratory centres to various cortical and sub-cortical regions implicated in the neurophysiology of breathlessness [38]. These regions, all of which express high densities of opioid receptors, include the prefrontal, insular and motor cortices, operculum, anterior and posterior cingulate cortices, amygdala and periaqueductal grey matter [38-42].

It is unlikely that awareness of reduced central neural respiratory drive was the only mechanism responsible for relief of exertional breathlessness and improved EET after taking morphine versus placebo, particularly in view of 1 ) the small reductions in $V^{\prime} \mathrm{E}, f \mathrm{R}$ and EMGdi at isotime relative to the large improvements in exertional breathlessness and EET and 2) our finding that exertional breathlessness was reduced and EET increased after taking morphine versus placebo within responders despite no statistically significant decreases in $V^{\prime} \mathrm{E}$ and $\mathrm{fR}$. It is possible that morphine relieved breathlessness and improved EET by suppressing activity of the cortico-limbic regions implicated in the perception of breathlessness, independent of, or in conjunction with, its effect on central neural respiratory drive [9, 38-40, 42].

Although one serious adverse event occurred in a participant with an unreported intolerance to opioids, no meaningful pre-to-post dose changes in any of the symptoms evaluated using the ORSDS were observed following the administration of immediate-release oral morphine in our participants with advanced COPD. These findings are consistent with the results of earlier studies that informally assessed opioid-related side effects in COPD $[8,10]$.

\section{Secondary exploratory analysis}

With the exception of $\mathrm{FEV}_{1} \%$ pred, which tended to be lower in responders versus non-responders, baseline participant characteristics, resting $\mathrm{PacCO}_{2}$, and plasma [MOR], [M3G] and [M6G] were similar between-groups (see table $\mathrm{E} 1$ in the online data supplement). Compared with non-responders, the responders subgroup 1) reported higher intensity and unpleasantness ratings of breathlessness at the symptom-limited peak of CPET and 2) were more likely to identify intolerable breathlessness as the 

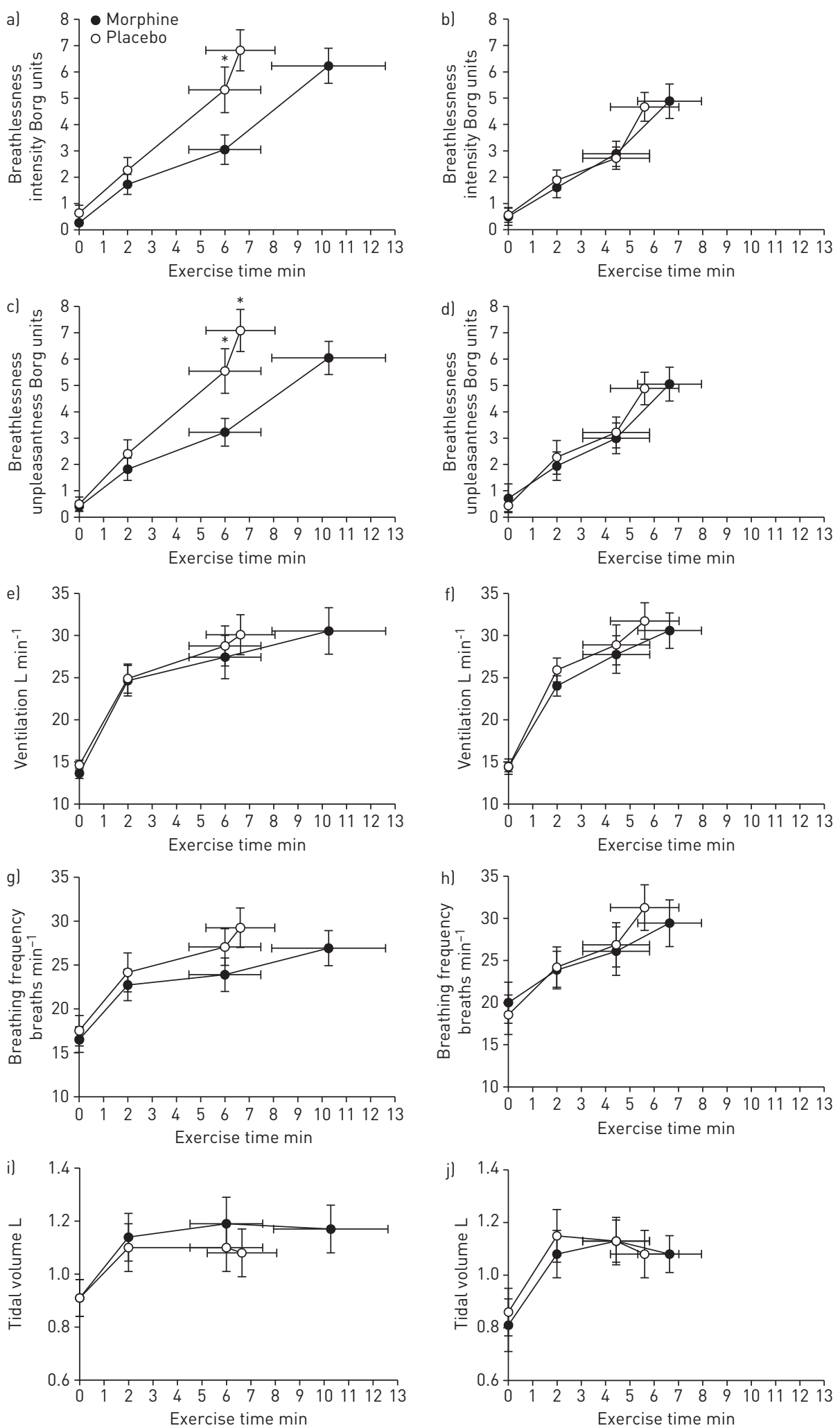

FIGURE 5 Effect of immediate-release oral morphine versus placebo on a and b) breathlessness intensity, $c$ and d) breathlessness unpleasantness, e and f) minute ventilation, $g$ and $h$ ) breathing frequency and $i$ and $j$ l tidal volume responses during constant-load cycle exercise testing at $75 \%$ of peak incremental power output in adults with advanced chronic obstructive pulmonary disease (COPD) and chronic breathlessness syndrome that did (responders ( $n=11)$; panels a,c,e,g and i) and did not (non-responders ( $n=9)$; panels b,d,f,h and j) report a decrease in breathlessness intensity of $\geqslant 1$ Borg unit during exercise at isotime after taking oral morphine versus placebo. Data are presented as mean \pm SEM. *: $p<0.05$ versus placebo. 
primary reason for stopping CPET, despite exercising to a similar PPO, EET, peak $V^{\prime} \mathrm{O}_{2}$ and peak $V^{\prime}$ E. Factors contributing to these between-group differences are unclear, particularly in the absence of notable differences in the physiological response to exercise. Collectively, these results suggest that adults with advanced COPD and chronic breathlessness syndrome who achieve relatively high ratings of breathlessness at the symptom-limited peak of exercise and/or who report intolerable breathlessness as their main exercise-limiting symptom may be the most responsive to immediate-release oral morphine. Although we were unable to elucidate the mechanism(s) responsible for the contrasting effect of oral morphine versus placebo on exertional breathlessness and EET in responders versus non-responders, we speculate that any one or combination of the following factors may be at least partly responsible: relatively greater morphine-induced suppression of central neural respiratory drive in responders versus non-responders, as evidenced by the 3.2 breath $\cdot \mathrm{min}^{-1}$ decrease in $f \mathrm{R}$ at isotime after taking morphine versus placebo within responders alone; unmeasured between-group differences in genetic variability (e.g. single nucleotide polymorphisms in opioid receptors) [43]; and unmeasured between-group differences in conditioned anticipatory/associative learning responses to breathlessness [42].

\section{Methodological considerations}

The generalizability of our results may be restricted to a relatively small and homogenous group of clinically stable, normocapnic, non-oxygen dependent and opioid-naïve adults with severe-to-very severe COPD and chronic breathlessness syndrome. The $0.1 \mathrm{mg} \cdot \mathrm{kg}^{-1}$ body mass dose of immediate-release oral morphine used in this trial may be considered relatively high, particularly in comparison to current recommendations on the use of opioids for managing refractory breathlessness in advanced COPD [12]. Dose-ranging studies are needed to identify the lowest effective dose of immediate-release oral morphine required to achieve clinically meaningful improvements in exertional breathlessness and EET in adults with advanced COPD and chronic breathlessness syndrome. We caution against the extrapolation of our results concerning the acute effect of single-dose immediate-release oral morphine on exertional symptoms in advanced COPD to other modes (e.g. inhaled, sublingual), types (e.g. fentanyl) and regimens of opioid administration (e.g. repeat-dose, sustained-release) in this patient population. Safety aspects of this trial should be interpreted cautiously as it was not powered to detect differences in safety outcomes. Although the results of our exploratory analysis may be limited by a small sample size (i.e. susceptible to a type 2 error), we nevertheless identified factors related to the locus of symptom-limitation on laboratory-based cycle CPET as being potentially helpful in identifying which patients will likely respond to a single-dose of immediate-release oral morphine, as previously demonstrated by DESCHENEs et al. [44] for bronchodilator therapy. In moving forward, it will be important to prospectively validate our post hoc classification of responders and non-responders by observing the effects of chronic dosing of morphine on breathlessness and exercise endurance in adults with advanced COPD and chronic breathlessness syndrome.

\section{Conclusions}

Single-dose administration of immediate-release oral morphine $\left(0.1 \mathrm{mg} \cdot \mathrm{kg}^{-1}\right.$ body mass $)$ was associated with statistically significant and clinically meaningful improvements in exertional breathlessness and exercise endurance in adults with advanced COPD and chronic breathlessness syndrome. The observed changes in breathlessness and exercise endurance after taking oral morphine versus placebo could not be explained by concurrent changes in cardiac, metabolic, gas exchange and/or dynamic operating lung volume responses to exercise but were associated with reductions in ventilation, breathing frequency and the diaphragm electromyogram during exercise at isotime. Although additional research is necessary, the locus of symptom-limitation on laboratory-based CPET has the potential to help healthcare providers better predict which patients with advanced COPD and chronic breathlessness syndrome are most likely to achieve clinically meaningful improvements in exertional breathlessness and exercise endurance in response to morphine.

\section{Acknowledgements}

The authors thank Cathy Fugere and Sarantis Koutelias (McConnell Centre for Innovative Medicine, RIMUHC, Montréal, QC, Canada) for their help with blood collection and Irina Uscatescu (McConnell Centre for Innovative Medicine) for her help with patient recruitment. The authors thank the COPD patients who participated in this study. Without their patience and support, this study would not have been possible.

\section{References}

1 Agusti A, Edwards LD, Celli B, et al. Characteristics, stability and outcomes of the 2011 GOLD COPD groups in the eclipse cohort. Eur Respir J 2013; 42: 636-646.

2 Mullerova $\mathrm{H}, \mathrm{Lu} \mathrm{C}, \mathrm{Li} \mathrm{H}$, et al. Prevalence and burden of breathlessness in patients with chronic obstructive pulmonary disease managed in primary care. Plos One 2014; 9: e85540.

3 Small M, Holbrook T, Wood R, et al. Prevalence and burden of dyspnoea among COPD patients in japan. Int $J$ Clin Pract 2016; 70: 676-681. 
4 Sundh J, Ekstrom M. Persistent disabling breathlessness in chronic obstructive pulmonary disease. Int J Chron Obstruct Pulmon Dis 2016; 11: 2805-2812.

5 Johnson MJ, Yorke J, Hansen-Flaschen J, et al. Towards an expert consensus to delineate a clinical syndrome of chronic breathlessness. Eur Respir J 2017; 49.

6 Ekstrom M, Nilsson F, Abernethy AA, et al. Effects of opioids on breathlessness and exercise capacity in chronic obstructive pulmonary disease. A systematic review. Ann Am Thorac Soc 2015; 12: 1079-1092.

7 Banzett RB, Adams L, O'Donnell CR, et al. Using laboratory models to test treatment morphine reduces dyspnea and hypercapnic ventilatory response. Am J Respir Crit Care 2011; 184: 920-927.

8 Light RW, Muro JR, Sato RI, et al. Effects of oral morphine on breathlessness and exercise tolerance in patients with chronic obstructive pulmonary disease. Am Rev Respir Dis 1989; 139: 126-133.

9 Pattinson KTS, Governo RJ, MacIntosh BJ, et al. Opioids depress cortical centers responsible for the volitional control of respiration. J Neurosci 2009; 29: 8177-8186.

10 Woodcock AA, Gross ER, Gellert A, et al. Effects of dihydrocodeine, alcohol, and caffeine on breathlessness and exercise tolerance in patients with chronic obstructive lung disease and normal blood gases. N Engl J Med 1981; 305: 1611-1616.

11 Mahler DA, Selecky PA, Harrod CG, et al. American College of Chest Physicians consensus statement on the management of dyspnea in patients with advanced lung or heart disease. Chest 2010; 137: 674-691.

12 Marciniuk DD, Goodridge D, Hernandez P, et al. Managing dyspnea in patients with advanced chronic obstructive pulmonary disease: a Canadian Thoracic Society clinical practice guideline. Can Respir J 2011; 18: 69-78.

13 Qaseem A, Wilt TJ, Weinberger SE, et al. Diagnosis and management of stable chronic obstructive pulmonary disease: a clinical practice guideline update from the American College of Physicians, American College of Chest Physicians, American Thoracic Society, and European Respiratory Society. Ann Intern Med 2011; 155: 179-191.

14 Vogelmeier CF, Criner GJ, Martinez FJ, et al. Global strategy for the diagnosis, management, and prevention of chronic obstructive lung disease 2017 report: GOLD executive summary. Am J Respir Crit Care Med 2017; 195: $557-582$.

15 Ahmadi Z, Bernelid E, Currow DC, et al. Prescription of opioids for breathlessness in end-stage COPD: a national population-based study. Int J Chron Obstruct Pulmon Dis 2016; 11: 2651-2657.

16 Young J, Donahue M, Farquhar M, et al. Using opioids to treat dyspnea in advanced COPD: attitudes and experiences of family physicians and respiratory therapists. Can Fam Physician 2012; 58: e401-e407.

17 Janssen DJ, de Hosson SM, bij de Vaate E, et al. Attitudes toward opioids for refractory dyspnea in COPD among dutch chest physicians. Chron Respir Dis 2015; 12: 85-92.

18 Fletcher CM, Elmes PC, Fairbairn AS, et al. The significance of respiratory symptoms and the diagnosis of chronic bronchitis in a working population. $\mathrm{Br}$ Med J 1959; 2: 257-266.

19 Mahler DA, Weinberg DH, Wells CK, et al. The measurement of dyspnea. Contents, interobserver agreement, and physiologic correlates of two new clinical indexes. Chest 1984; 85: 751-758.

20 McGavin CR, Artvinli M, Naoe H, et al. Dyspnoea, disability, and distance walked: comparison of estimates of exercise performance in respiratory disease. $\mathrm{Br}$ Med J 1978; 2: 241-243.

21 Jones PW, Harding G, Berry P, et al. Development and first validation of the COPD assessment test. Eur Respir 2009; 34: 648-654.

22 Zigmond AS, Snaith RP. The hospital anxiety and depression scale. Acta Psychiatr Scand 1983; 67: 361-370.

23 Apfelbaum JL, Gan TJ, Zhao S, et al. Reliability and validity of the perioperative opioid-related symptom distress scale. Anesth Analg 2004; 99: 699-709.

24 Yadeau JT, Liu SS, Rade MC, et al. Performance characteristics and validation of the opioid-related symptom distress scale for evaluation of analgesic side effects after orthopedic surgery. Anesth Analg 2011; 113: 369-377.

25 Macintyre N, Crapo RO, Viegi G, et al. Standardisation of the single-breath determination of carbon monoxide uptake in the lung. Eur Respir J 2005; 26: 720-735.

26 Miller MR, Crapo R, Hankinson J, et al. General considerations for lung function testing. Eur Respir J 2005; 26 $153-161$.

27 Miller MR, Hankinson J, Brusasco V, et al. Standardisation of spirometry. Eur Respir J 2005; 26: 319-338.

28 Wanger J, Clausen JL, Coates A, et al. Standardisation of the measurement of lung volumes. Eur Respir J 2005; 26 : 511-522.

29 Jensen D, Alsuhail A, Viola R, et al. Inhaled fentanyl citrate improves exercise endurance during high-intensity constant work rate cycle exercise in chronic obstructive pulmonary disease. J Pain Symptom Manage 2012; 43: 706-719.

30 Guenette JA, Chin RC, Cory JM, et al. Inspiratory capacity during exercise: measurement, analysis, and interpretation. Pulm Med 2013; 2013: 956081.

31 Borg GA. Psychophysical bases of perceived exertion. Med Sci Sports Exerc 1982; 14: 377-381.

32 Mendonca CT, Schaeffer MR, Riley P, et al. Physiological mechanisms of dyspnea during exercise with externa thoracic restriction: role of increased neural respiratory drive. J Appl Physiol 2014; 116: 570-581.

33 Schaeffer MR, Mendonca CT, Levangie MC, et al. Physiological mechanisms of sex differences in exertional dyspnoea: role of neural respiratory motor drive. Exp Physiol 2014; 99: 427-441.

34 O'Donnell DE, Hong HH, Webb KA. Respiratory sensation during chest wall restriction and dead space loading in exercising men. J Appl Physiol 2000; 88: 1859-1869.

35 Faul F, Erdfelder E, Buchner A, et al. Statistical power analyses using g*power 3.1: tests for correlation and regression analyses. Behav Res Methods 2009; 41: 1149-1160.

36 Ries AL. Minimally clinically important difference for the UCSD shortness of breath questionnaire, Borg scale, and visual analog scale. Copd 2005; 2: 105-110.

37 Puente-Maestu L, Villar F, de Miguel J, et al. Clinical relevance of constant power exercise duration changes in COPD. Eur Respir J 2009; 34: 340-345.

38 von Leupoldt A, Dahme B. Cortical substrates for the perception of dyspnea. Chest 2005; 128: 345-354.

39 Herigstad M, Hayen A, Evans E, et al. Dyspnea-related cues engage the prefrontal cortex: evidence from functional brain imaging in copd. Chest 2015; 148: 953-961.

40 Pattinson KTS. Opioids and the control of respiration. Br J Anaesth 2008; 100: 747-758 
41 Baumgartner U, Buchholz HG, Bellosevich A, et al. High opiate receptor binding potential in the human lateral pain system. Neuroimage 2006; 30: 692-699.

42 Hayen A, Wanigasekera V, Faull OK, et al. Opioid suppression of conditioned anticipatory brain responses to breathlessness. Neuroimage 2017; 150: 383-394.

43 Currow DC, Quinn S, Ekstrom M, et al. Can variability in the effect of opioids on refractory breathlessness be explained by genetic factors? BMJ Open 2015; 5: e006818.

44 Deschenes D, Pepin V, Saey D, et al. Locus of symptom limitation and exercise response to bronchodilation in chronic obstructive pulmonary disease. J Cardiopulm Rehabil Prev 2008; 28: 208-214. 